Japan. J. Med. Sci. Biol., 24, 125-127, 1971

\title{
NOTE
}

\section{VIBRIO AGAR: A NEW PLATING MEDIUM FOR ISOLATION OF VIBRIO CHOLERAE}

Although large varieties of agar media have been reported for the isolation of Vibrio cholerae, TCBS agar and alkaline bile salt agar are the most commonly used.

TCBS agar was devised by Kobayashi et al. (1963) and confirmed to be satisfactory in an extensive field trial during the Joint Japan-Philippines-WHO Cholera Studies. TCBS agar is a highly selective medium for $V$. cholerae, but the selectivity is sometimes insufficient to surpress the growth of Proteus, Aeromonas and enterococci, especially, when the plate is used for secondary isolation of the vibrio after enrichment of the fecal specimens in alkaline peptone water. In those instances, differentiation of the $V$. cholerae colony from those of contaminants is somewhat difficult because the latter also forms sucrose-fermenting yellow colony resembling that of $V$. cholerae. In addition to this, the $V$. cholerae colony growing on TCBS agar plate shows some difficulty to be agglutinated with $V$. cholerae O-1 antiserum. Due to the high selectivity of the agar, some strains of $V$. cholerae especially classical and non-agglutinable strains, fail to grow on the agar plate. Many workers recommended, therefore, that alkaline bile salt agar be used together with TCBS agar to avoid such unpredictable lapses.

Alkaline bile salt agar is less selective and not a differential medium and much experience is necessary to use this agar. Although $V$. cholerae may be detected on alkaline bile salt agar with great ease when the oblique light technique is used, the technique is very time-consuming and therefore cannot be employed for the observation of a large number of plates in routine examination.

Recently, a new plating medium, Vibrio agar, has been development by "Nissui Seiyaku Co." in Japan for the isolation of Vibrio parahaemolyticus. However, the agar was somewhat insufficient for growth and differentiation of $V$. cholerae. During the course of the Cholera Carrier and Serological Studies in Calcutta under the joint auspices of the Indian Council of Medical Research, West Bengal Government Health Department and WHO in 1969, the authors revised the formula of the original Vibrio agar. The final formula of the revised Vibrio agar is as follows:

Yeast extract (Difco), $5 \mathrm{~g}$; trypticase (BBL), $4 \mathrm{~g}$; proteose peptone (Difco), $3 \mathrm{~g}$; sucrose, $20 \mathrm{~g}$; sodium thiosulfate $\left(5 \mathrm{H}_{2} \mathrm{O}\right), 6.5 \mathrm{~g}$; sodim citrate $\left(2 \mathrm{H}_{2} \mathrm{O}\right), 10 \mathrm{~g}$, sodium deoxycholate, $1 \mathrm{~g}$; sodium chloride, $10 \mathrm{~g}$; ox bile (depigmented solids), $5 \mathrm{~g}$; sodium lauryl sulfate, $0.2 \mathrm{~g}$; water blue, $0.2 \mathrm{~g}$; cresol red, $0.02 \mathrm{~g}$; agar, $15 \mathrm{~g}$; distilled water, $1,000 \mathrm{ml}$. Final $\mathrm{pH} 8.5$.

The selectivity of the revised Vibrio agar was less than that of TCBS agar, but more than that of alkaline bile salt agar. The $V$. cholerae colony on Vibrio agar was bluish gray, transluscent and sticky; it was larger than the colonies of other organisms, and also than the $V$. cholerae colony on TCBS agar. Colonies of sucrosefermenting contaminants such as Proteus and Aeromonas were more blue and smaller 
on Vibrio agar and easily distinguishable from the vibrio colony, while the $V$. cholerae colony could not be differentiated in appearance from that of contaminants on TCBS agar. In addition, the stickiness of the $V$. cholerae colony seemed to be an important distinguishable character. Sometimes, Klebsiella grew on Vibrio agar forming a large colony which could be easily differentiated from that of $V$. cholerae because of its mucoid and opaque appearance. The $V$. cholerae colony on Vibrio agar was more easily agglutinated with $V$. cholerae O-1 antiserum than that on TCBS agar.

The revised Vibrio agar, which was sent from Nissui Seiyaku in dehydrated form, was compared with TCBS agar (Eiken) and alkaline bile salt agar for the isolation of $V$. cholerae by using 400 stool specimens obtained from the cholera field in Calcutta. Stool swabs or rectal swabs were collected into alkaline peptone water or Monsur's tellurite bile salt broth, and after 6 to $8 \mathrm{hr}$ incubation, each of a loopful of the culture was streaked onto the three plates mentioned above. After overnight incubation at $37 \mathrm{C}$, suspicious colonies on each of the plates were tested with $V$. cholerae O-1 antiserum by slide agglutination. Colonies agglutinated with the antiserum were then subcultured onto/into TSI agar, SIM medium, VP medium and lysine decarboxylase medium for further biochemical and serological tests for the identification of $V$. cholerae.

The results of the isolation of $V$. cholerae on the three plates are summarized in Table 1.

Table 1. Comparison of Vibrio agar, TCBS agar and alkaline bile salt agar for isolation of $V$. cholerae from 400 stool specimens

\begin{tabular}{|c|c|c|c|}
\hline \multicolumn{3}{|c|}{ Isolation of $V$. cholerae on } & \multirow{2}{*}{$\begin{array}{l}\text { Number of } \\
\text { specimens }(\%)\end{array}$} \\
\hline Vibrio agar & TCBS agar & $\begin{array}{l}\text { Alkaline } \\
\text { bile salt agar }\end{array}$ & \\
\hline+ & + & + & $92(23.0)$ \\
\hline+ & + & - & $31(7.7)$ \\
\hline+ & - & + & $3(0.8)$ \\
\hline- & + & + & 0 \\
\hline+ & - & - & $14(3.5)$ \\
\hline- & + & - & $2(0.5)$ \\
\hline- & - & + & 0 \\
\hline- & - & - & $258(64.5)$ \\
\hline Total & & & $400(100)$ \\
\hline
\end{tabular}

These results suggest that the revised Vibrio agar is a satisfactory medium for the isolation of $V$. cholerae. It was considered that more frequent detection of $V$. cholerae on Vibrio agar than on TCBS agar was due to the easily differential appearance of the $V$. cholerae colony from that of other organisms. This fact would be important for the bacteriologist who is inexperienced in the examination of cholera specimens.

It should be noted that all positive cases on alkaline bile salt agar also gave positive results on either, or both, Vibrio agar and TCBS agar. The results may 
show that alkaline bile salt agar is not at all efficient as a medium for the cholera studies without application of the oblique light technique. The results obtained here were quits opposite to a study by De et al. (1968) who reported that better isolation of $V$. cholerae was obtained on alkaline bile salt agar rather than on TCBS agar.

Although more frequent detection of $V$. cholerae was given on Vibrio agar than on TCBS agar in this study, the authors considered that TCBS agar is not necessarily inferior to Vibrio agar. It is possible that more frequent isolation of $V$. cholerae may be obtained on TCBS agar if another study were carried out elsewhere. In fact in the comparative study, two of the 400 specimens examined here gave positive results only on TCBS agar. It may be difficult, therefore, to measure any superiority between TCBS and Vibrio agar.

On the basis of these results, it is recommended that Vibrio agar should be employed together with TCBS agar, instead of alkaline bile salt agar, in routine cholera studies.

The authors wish to express their appreciation to Dr. R. Sakazaki for his helpful advice and suggestion. They also wish to acknowledge the facilities and assistance they received in connection with their studies from Drs. Z. Bencic, WHO Cholera Team and R. Sinha, Medical Officer, Health Department of West Bengal Government, India.

\section{REFERENCES}

DE, S. P., Ghosh, A. K. AND DE, S. P., Jr. (1968): A comparison of TCBS agar and bile salt agar media for the isolation of $V$. cholerae. Ind. J. Med. Res., 56, 1478-1481.

Kobayashi, T., ENomoto, S., SAKazaki, R. AND Kuwahara, S. (1963): A new selective isolation medium for pathogenic vibrios. TCBS agar (Modified Nakanishi's agar). Japan. J. Bacteriol., 18, 387-391. (text in Japanese).

Department of Bacteriology I

KAZUMICHI TAMURA*

National Institute of Health

Shinagawa-ku, Tokyo 141, Japan

Division of Research

SHIGERU SHIMADA**

Nissui Seiyaku Co. Ltd.

Sendagi, Bunkyo-ku, Tokyo 113, Japan

Cholera Research Centre

L. M. PRESCOTT

Calcutta, India

* 田村和満 (国立予防衛生研究所 細菌第 1 部)

** 島田 茂（日水製薬株式会社, 文京区千駄木 3-22-10) 